\title{
Oxidative pyrolysis of pine wood, wheat straw and miscanthus pellets in a fixed bed
}

\author{
Xuan-Huynh Pham ${ }^{\mathrm{a}, \mathrm{b}, *}$, Bruno Piriou ${ }^{\mathrm{a}}$, Sylvain Salvador ${ }^{\mathrm{c}}$, Jeremy Valette ${ }^{\mathrm{a}}$, \\ Laurent Van de Steene ${ }^{\mathrm{a}, \mathrm{b}}$ \\ a CIRAD, UPR BioWooEB, F-34398 Montpellier, France \\ ${ }^{\mathrm{b}}$ Department of Energy, University of Science and Technology of Hanoi, Vietnam Academy of Science and Technology, 18 Hoang Quoc Viet, Hanoi, Viet Nam \\ ${ }^{c}$ RAPSODEE, CNRS UMR 5203, Mines-Albi, Campus Jarlard, 81013 Albi Cedex 09, France
}

Oxidative pyrolysis is a key step in the autothermal operation of many fixed-bed reactors for staged gasification and advanced carbonisation. In these reactors, biomass is converted into charcoal, condensates and permanent gases inside a moving Oxidation Zone $(\mathrm{OZ})$ which also produces energy to self-sustain the process. Oxidative pyrolysis of three different biomass types: pine wood, miscanthus and wheat straw pellets, was performed in a batch $20 \mathrm{~cm}$ diameter fixed bed reactor. Results showed that the OZ consumed $11 \%$ to $14 \%$ of the stoichiometric air to self-sustain the process and reached a peak temperature around $720^{\circ} \mathrm{C}$ whatever the biomass. The propagation velocity and thickness of the $\mathrm{OZ}$ were inversely proportional to the ash content and to the bulk density of the biomass. Ash was also shown to influence the yield and composition of the resulting products due to a catalytic effect on primary and secondary pyrolysis reactions.

Keywords:

Oxidative pyrolysis

Oxidation zone

Fixed bed

Biomass

Smouldering

\section{Introduction}

Energy production from lignocellulosic biomass has been receiving increased attention in recent years as it has many advantages including reducing reliance on fossil fuels, reducing energy shortages, contributing to environmental protection and providing benefits for rural habitats. Thermochemical processes allow the conversion of chemical energy from the biomass into convenient energy such as heat, electricity or fuel. Three main commercial technologies are available depending on the application: fixed bed, fluidized bed, and entrained flow. Fixed bed reactors, of updraft or downdraft type, are widely acknowledged to be particularly suitable for the carbonisation or gasification of woody biomass because they are simpler, more robust, and cheaper to produce. However, extending the range of biomass type to fibrous and low density resources is complex because of technical problems such as bridging and jamming currently encountered with this type of reactor. Moreover, the use of biomass requires overcoming logistic problems involved in their storage, transport and supply. Pelletizing is thus a good alternative way to extend the range of biomass which can be used for fixed bed gasification or carbonisation [1]. In addition, the insertion of a pelletizing step may also allow to consider the use of blends of agricultural, forestry [2] and industrial by-products such as paper industry wastes [3].
In thermochemical processes, pyrolysis plays a major role in producing char, condensates and permanent gases for subsequent reactions. When pyrolysis is considered separately from the rest of the process, one question is the way the energy required for the endothermic heating/drying/pyrolysis of the biomass is supplied. One standard efficient way is through partial oxidation of the biomass itself by injecting a low air mass flux. In this case, the pyrolysis is autothermal and refers to oxidative pyrolysis [4].

In a fixed bed configuration, oxidative pyrolysis occurs in a zone of the packed bed called the oxidation zone, which propagates towards the fresh biomass and produces char, condensates and gases. The propagation of the oxidation zone in a porous media is called "smouldering". It has been studied in many contexts, including forest fires [5,6] organic soil or house fires [7], underground fires in coal mines [8], waste and biomass incineration [8] or biomass gasification [7]. Smouldering can be natural or forced depending on the way the air penetrates the porous medium. Depending on the relative direction of the propagation of the oxidation zone and the air supply, the smouldering is said to be countercurrent and co-current. In counter-current smouldering, the oxidation zone propagates inversely to the direction of the air flow, whereas in cocurrent smouldering, the oxidation zone and the air flow propagate in the same direction.

We investigated the forced counter-current smouldering

* Corresponding author at: CIRAD, UPR BioWooEB, F-34398 Montpellier, France.
E-mail address: huynh.pham_xuan@cirad.fr (X.-H. Pham). 
configuration in a pyrolysis downdraft fixed bed reactor, and analysed the behaviour of the oxidation zone with three different kinds of pelletized biomass.

The oxidation zone can be described by several specific features: (i) propagation rate, (ii) temperature, (iii) geometry, such as thickness and shape, (iv) yields and the composition of the resulting char, condensates, and permanent gases. Among these features, the propagation rate, which is controlled by many reactions and heat and mass transfers, is widely investigated in the literature on counter-current smouldering. These studies [1,9-14] show that the propagation rate depends on the air mass flux, fuel properties and bed properties. However, the interdependence of all these parameters makes it difficult to draw specific conclusions about the impact of each separate parameter on the behaviour of the oxidation zone [11].

Nevertheless, the major influence of air mass flux is acknowledged by all authors. Many studies have highlighted its impact on the propagation rate [1,9-14], and temperature [11,13], but fewer on the geometry of the oxidation zone $[9,10]$. It has been reported that the propagation rate inside a biomass packed bed initially increases along with the air mass flux until it reaches a peak. A further increase in the air mass flux then reduces the propagation rate. Three different regimes - oxygen limited, reaction limited and quenching by convection - are usually identified in counter-current smouldering applied to the combustion process. The regimes are determined by the main process controlling the propagation of the oxidation zone $[9,14,15]$.

The influence of the nature of the biomass or bed properties has been the object of fewer investigations. A few studies have shown that the propagation rate is higher when: (i) particle size $[9,14,15]$, moisture content $[8,13,15]$ and ash content [13] are low or (ii) when the heating value is high $[14,15]$. In addition, the propagation rate has been shown to be inversely proportional to bed bulk density $[4,9,16]$. Regarding the geometry of the oxidation zone, some authors have attempted to measure the thickness of the ignition zone in counter-current combustion processes $[9,10]$. The thickness has been reported to be proportional to particle size, and not to be sensitive to the air mass flux [10]. The shape of the oxidation zone has been shown to be flat and horizontal in a wood pellet bed but inclined and less stable in a wood chip bed [4].

Regarding the products of oxidative pyrolysis, some authors [17] reported that the yields of organic condensates were lower than those in inert pyrolysis, whereas the production of pyrolysis water and permanent gases was higher. Zhao et al. [12] investigated the influence of oxygen and showed that its presence improved the yields of permanent gas and water, but reduced the yields of char and condensates. $\mathrm{CO}$ and $\mathrm{CH}_{4}$ were mostly released between $300{ }^{\circ} \mathrm{C}$ and $400{ }^{\circ} \mathrm{C}$ and their production decreased at higher temperatures.

Some remarks need to be made before positioning the present work. First, we need to emphasise that almost all the research related to forced counter-current smouldering has been performed with high air flux compared to studies of oxidative pyrolysis. Indeed, in those studies, air flux varied from stoichiometry conditions (equivalence ratio equal to 1 ) to fit combustion applications, down to gasification ones with equivalence ratio close to 0.25 . Several authors $[10,11,13]$ investigated a lower air flux but none as low as the level in the present study. Thus, information is missing on the propagation rate, geometry, and conversion during counter-current smouldering in packed bed in very low air flux conditions. Moreover, it has also been reported that with such a small air mass flux, steady state regime is difficult to reach [10]. Secondly, very little information is available on the influence of the nature of the biomass on the features of the oxidation zone; quantitative results in particular, would advance our understanding of the process. And finally, in counter-current smouldering in a downdraft reactor, compaction occurs in the oxidation zone and thus needs to be taken into consideration for a global understanding and potential applications.

We investigated counter-current smouldering in a continuous fixed bed reactor with woody biomass in two previous studies $[4,17]$. The influence of air flux and bed density on oxidative pyrolysis was studied in low air flux conditions, but the continuous operation mode did not allow the fine characterisation of the propagation rate and the geometry of the oxidation zone. What is more, propagation velocity and front temperature are key processing features that cannot be controlled by the operators when the biomass type is changed. It is thus essential to identify and understand the main impacts of biomass properties on these particular processing features during oxidative pyrolysis.

The aim of the present work was thus to focus on the characterisation of the oxidative pyrolysis of biomass pellets in a downdraft fixed bed reactor in batch operating conditions under a low air flux of $0.022 \mathrm{~kg} \mathrm{~m}^{-2} \mathrm{~s}^{-1}$. This value was chosen as a representative air mass flux for the pyrolysis stage of an industrial gasifier. Three different pelletized biomasses were selected: one representative of forestry (pine), one representative of agricultural residues (wheat straw), and one representative of energy crops (miscanthus). Our specific objective was to investigate the influence of their physical properties and chemical composition on the features of the oxidation zone. We measured the propagation rate, thickness, temperature field, compaction rate, yields and composition of the pyrolysis products.

This paper provides new insight into the behaviour of oxidation zone propagation in a counter-current smouldering configuration. It supports research for the validation or development of CFD models, as well as for designers and operators in the optimisation of their process design and operation.

\section{Experimental devices and procedure}

\subsection{Description of the equipment}

The study was carried out in a fixed bed reactor with an internal diameter of $20 \mathrm{~cm}$ (Fig. 1), and previously described by [4,17,18]. It consists of a 310 type refractory steel tube $(160 \mathrm{~cm} \mathrm{~L})$ surrounded by $30 \mathrm{~cm}$ thick refractory wool insulation. Thermocouples were installed at $10 \mathrm{~cm}$ intervals inside the bed to enable measurement of the temperature profile. In addition, a laser beam device was placed above the biomass bed to continuously measure the bed height during the experiments, thus allowing calculation of bed compaction.

Biomass and air are fed in at the top of the reactor. The pyrolysis products are collected at the bottom, below the grate. The pyrolysis flue gas is sent to a flare burner. After an experiment, the grate is lowered; the char is extracted from the reactor and collected in a char tank. The fine particulates are trapped by a cyclone. A sampling pipe is inserted below the grate to collect both condensable and non-condensable gases. The sampling train adapted from the tar protocol [19] consists in a series of eight impingers. The first two impingers are empty and maintained at ambient temperature, followed by four impingers at $20^{\circ} \mathrm{C}$ : two impingers are filled with isopropanol and the remaining six are empty. Finally, two silica gel and cotton impingers at ambient temperature allow absorption of all the residual tars and water and protect the Micro-GC system.

Proximate analyses of biomass and char were carried out in a muffle furnace according to standards AFNOR NF EN 1860-2 and AFNOR XP CENT/TS 14775. Ultimate analyses were performed using a Vario Macro Cube Elemental analyser. Permanent gases were analysed online with a VARIAN $\mu \mathrm{GC}$, equipped with a TCD detector with two columns: MolSieve 5A and PoraPlotQ for permanent gases including $\mathrm{O}_{2}, \mathrm{~N}_{2}, \mathrm{CO}$, $\mathrm{CO}_{2}, \mathrm{H}_{2}, \mathrm{CH}_{4}, \mathrm{C}_{2} \mathrm{H}_{4}$, and $\mathrm{C}_{2} \mathrm{H}_{6}$.

\subsection{Biomass feedstocks}

Three different biomasses of different nature and origin were selected: miscanthus as a representative of herbaceous energy crops, wheat straw as a widespread agricultural residue and pine wood as a representative of forestry residues. As discussed in the introduction, we used biomass in pellet form. The biomass pellets were all homogeneous 


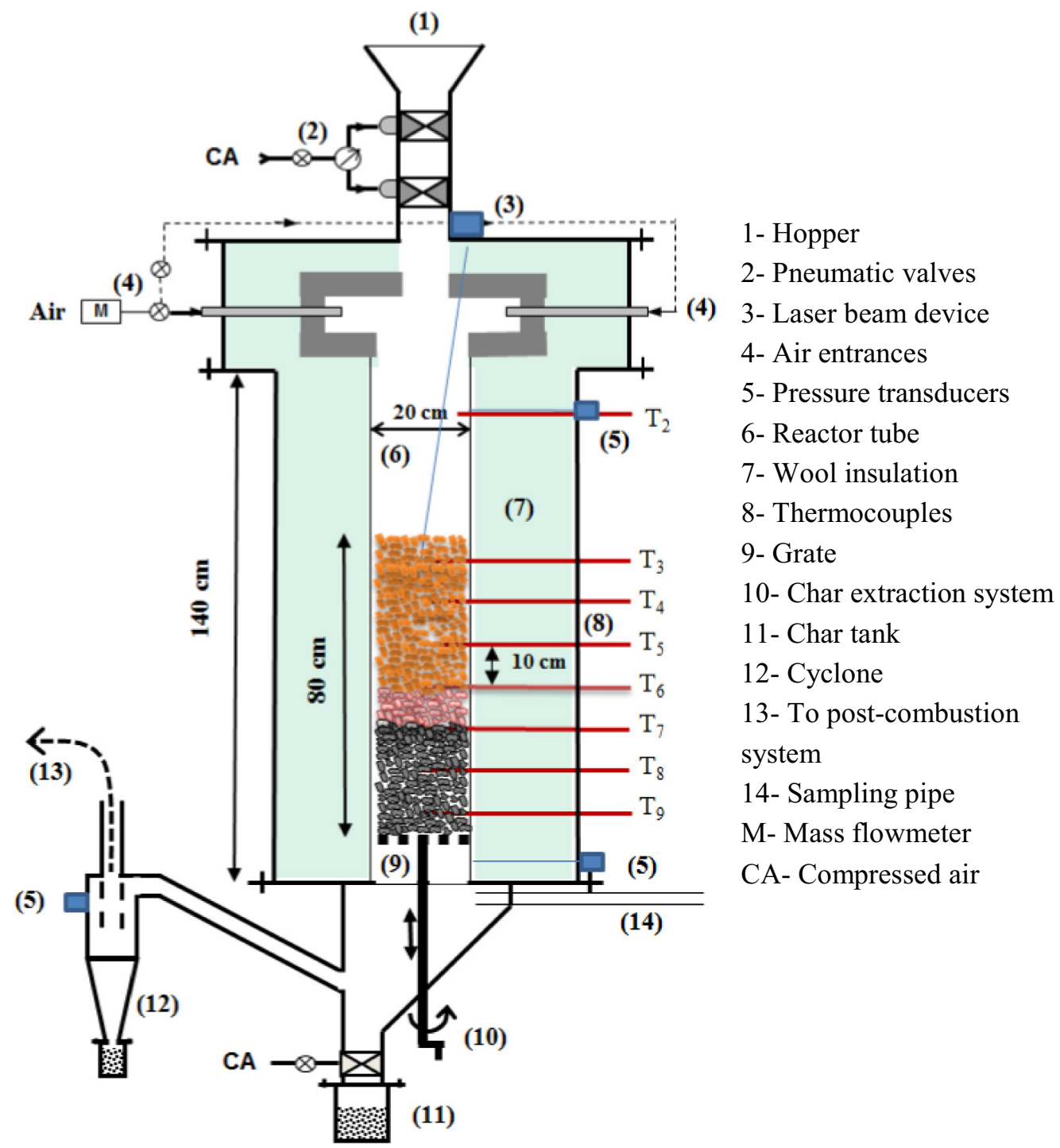

Fig. 1. The fixed bed reactor.

Table 1

Proximate and ultimate analyses of the biomasses.

\begin{tabular}{llll}
\hline Biomass & Pine & Miscanthus & Wheat straw \\
\hline Moisture $(\mathrm{wt} \%, w b)$ & 7.0 & 7.9 & 8.8 \\
Proximate analysis $(\mathrm{wt} \%, d b)$ & & & \\
Ash & 0.28 & 2.98 & 8.17 \\
Volatile matter & 82.13 & 84.83 & 78.75 \\
Fixed carbon & 17.59 & 12.19 & 13.08 \\
Ultimate analysis $(\mathrm{wt} \%$, daf) & & & \\
$\mathrm{C}$ & 54.80 & 57.87 & 58.91 \\
$\mathrm{H}$ & 5.65 & 5.04 & 5.07 \\
$\mathrm{~N}$ & 0.09 & 0.24 & 1.10 \\
O (by difference) & 39.46 & 36.86 & 34.92 \\
LHV (MJ kg $\left.{ }^{-1}, d b\right)$ & 21.76 & 20.04 & 19.12 \\
Bulk density $\left(\mathrm{kg} \mathrm{m}^{-3}\right)$ & 657 & 584 & 549 \\
\hline
\end{tabular}

in size, with a diameter of $6 \mathrm{~mm}$ and a length of around $20 \mathrm{~mm}$. Biomasses were purchased from commercial outlets: pine from Bioforest $^{\circledast}$, miscanthus from Jardi'nova ${ }^{\circledR}$ and wheat straw pellets from $\mathrm{RAGT}^{\circledR}$. The results of proximate and ultimate analyses are listed in Table 1.

The main difference in composition concerned ash content, which ranged from $0.28 \%$ for pine wood to $2.98 \%$ for miscanthus and $8.17 \%$ for wheat straw. Volatile matter contents differed slightly. The low heating value (LHV) was $21.76 \mathrm{MJ} \mathrm{kg}^{-1}$ for pine, followed by $20.04 \mathrm{MJ} \mathrm{kg}^{-1}$ for miscanthus and $19.12 \mathrm{MJ} \mathrm{kg}^{-1}$ for wheat straw.

The moisture contents of the three biomasses were $7.0 \%$ for pine, $7.9 \%$ for miscanthus to $8.8 \%$ for wheat straw. In order to investigate the influence of moisture content on the oxidation zone, we dried some miscanthus pellets in a climate controlled chamber with $15 \%$ relative humidity for $48 \mathrm{~h}$ at a temperature of $50{ }^{\circ} \mathrm{C}$. The resulting moisture content of was $3.9 \%$.

\subsection{Experimental procedure}

The oxidation zone (OZ) was ignited at the surface of a $10 \mathrm{~cm}$ layer of char at the bottom of the reactor by dropping some barbeque starters onto the surface of the layer of charcoal. During this step, a high air flux of $90 \mathrm{NL} \mathrm{min}{ }^{-1}$ was supplied to accelerate combustion in the layer of charcoal and obtain a homogeneous OZ covering the whole surface of the reactor. Correct ignition was verified when the temperature at T9 reached $950{ }^{\circ} \mathrm{C}$ (Fig. 2). After ignition of the $\mathrm{OZ}$, the air flow from the top of the reactor was reduced to the value to be investigated in the test of $34 \mathrm{NL} \mathrm{min}{ }^{-1}\left(0.022 \mathrm{~kg} \mathrm{~m}^{-2} \mathrm{~s}^{-1}\right)$, and the reactor was filled with biomass pellets to a height of about $80 \mathrm{~cm}$ above the grate (about $10 \mathrm{~cm}$ of charcoal and $70 \mathrm{~cm}$ of biomass). The $\mathrm{OZ}$ then propagates upward and 


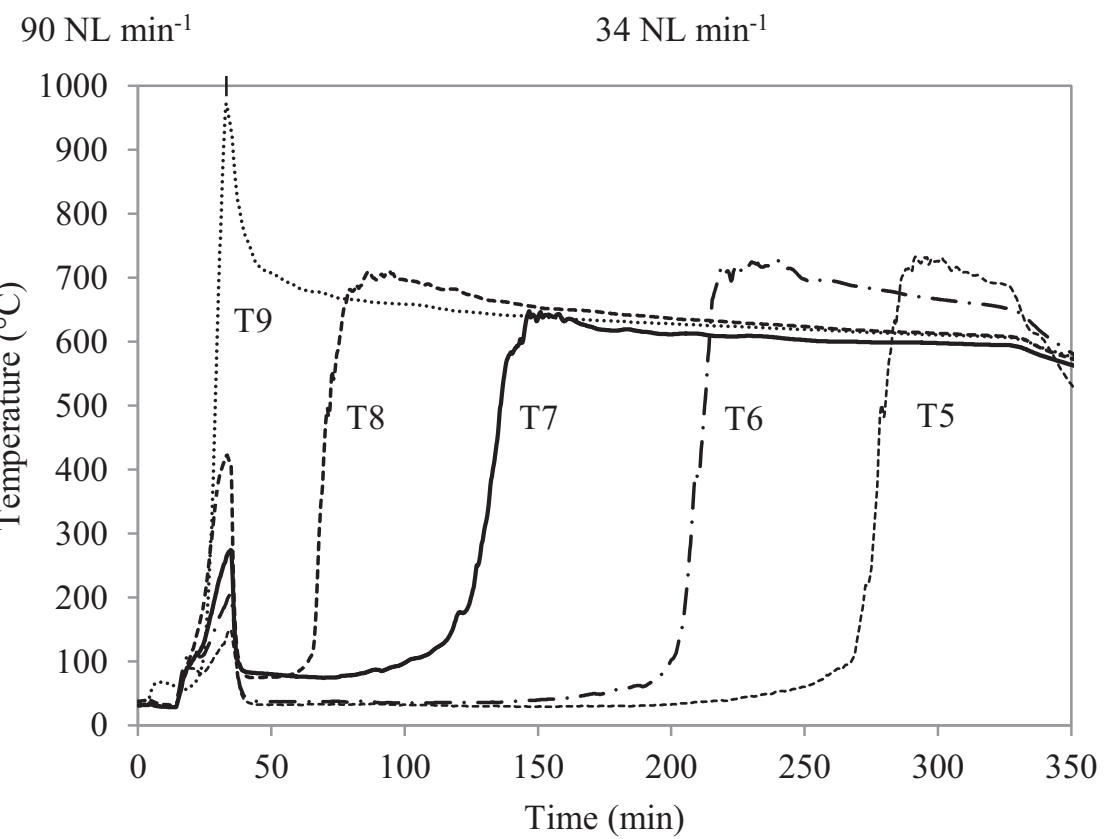

Fig. 2. A typical temperature versus time profile obtained from an experiment with pine pellets, $0.022 \mathrm{~kg} \mathrm{~m}^{-2} \mathrm{~s}^{-1}$ air flux.

can be monitored by the increase in temperature measured successively at $10 \mathrm{~cm}$ intervals by thermocouples.

First, at T9, we observed a rise in temperature up to $950-1000{ }^{\circ} \mathrm{C}$ at $30 \mathrm{~min}$. The temperature then dropped to around $650^{\circ} \mathrm{C}$ as a consequence of the reduction in the air flux to the studied value of $34 \mathrm{NL} \mathrm{min}^{-1}$ and the introduction of biomass. Finally, the temperature remained almost stable while the OZ propagated upward to the other thermocouples right up to the end of the experiment.

The oxidation zone propagated upward from position T9 to the top of the bed. Note that at the end of the experiment, the top of the bed was below $\mathrm{T} 4$ because of compaction of the bed. The temperature profiles versus time were used to measure the propagation velocity of the oxidation zone in the biomass bed. Details on this method are provided in the following section.

The gas was sampled during propagation of the OZ from T7 to T5, over a distance of $20 \mathrm{~cm}$ assumed during the stationary regime. Each experiment was performed three times in order to check repeatability, after which the average measurements were calculated.

\section{Methods for characterising the oxidation zone}

\subsection{Propagation velocities of the oxidation zone and bed compaction}

In this counter-current smouldering configuration, the oxidation zone propagates upwards. The bottom of the bed but mainly the $\mathrm{OZ}$ may undergo compaction, forcing the bed to slowly flow downward. As a consequence, we define (Fig. 3):

- The apparent propagation velocity, Voz/reactor, as the OZ upward velocity calculated from the location of the $\mathrm{OZ}$ at different times.

- The effective propagation velocity, Voz/biomass, as the velocity of the $\mathrm{OZ}$ related to the virgin biomass. This velocity refers to a term commonly referred to in the literature as "front propagation velocity", "ignition velocity" or "flame speed".

Considering the compaction of the bed, the effective velocity can be calculated from the measured apparent velocity according to Eq. (1):

$V_{O Z / \text { biomass }}=V_{O Z / \text { reactor }}+V_{C}$

where the compaction velocity $V_{C}$ is defined as the downward velocity of

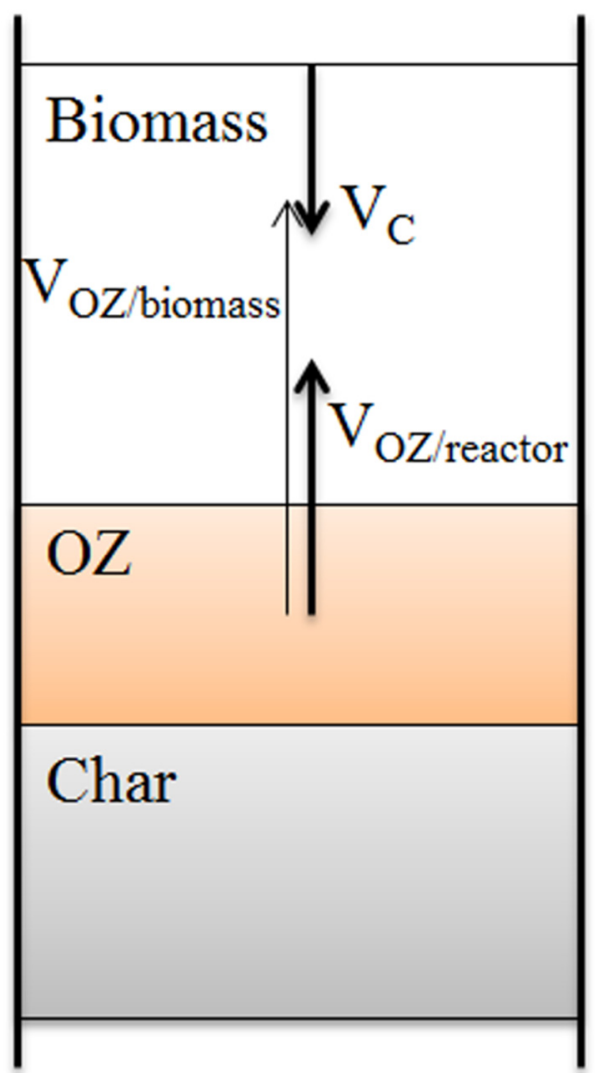

Fig. 3. Schematic representation of OZ propagation velocities and compaction velocity.

the virgin biomass bed caused by compaction in the OZ. Assuming no compaction in the virgin biomass bed, the compaction velocity is calculated as the derivative of the total bed height versus time. The bed height is measured by the laser beam.

Compaction can be caused by shrinkage, fragmentation, and rearrangement of biomass particles during the conversion, as the 


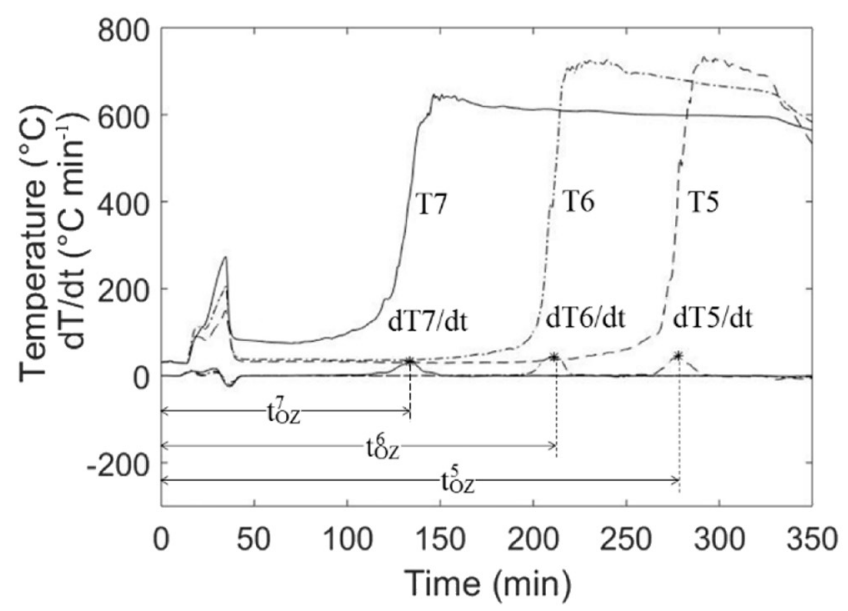

(a)

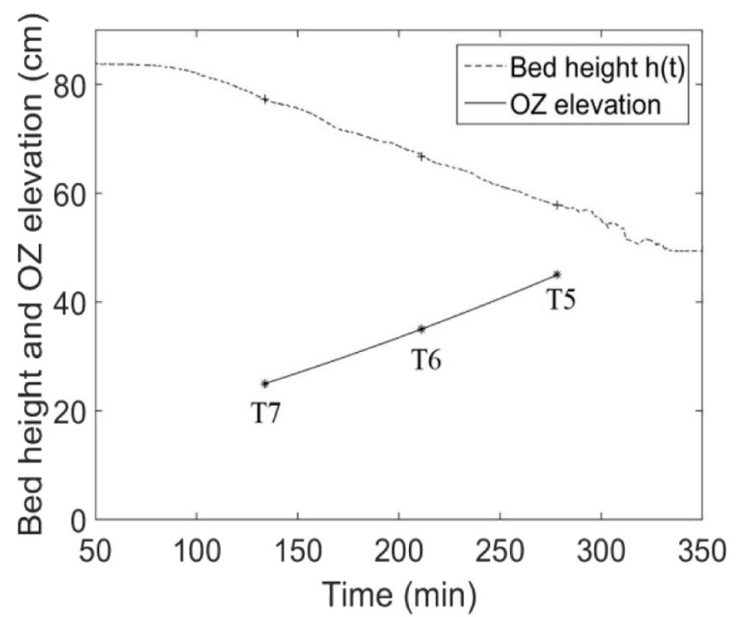

(b)

Fig. 4. Determination of the OZ velocities: (a) The time of passage of the oxidation zone (b) Bed compaction and $\mathrm{OZ}$ propagation: pine pellets, $0.022 \mathrm{~kg} \mathrm{~m}^{-2} \mathrm{~s}^{-1}$ air flux.

consequences of a number of coupled chemical and mechanical phenomena $[16,20]$.

We also define the effective propagation rate, $\dot{m}_{O Z}$, as the flux of biomass consumed by the oxidation zone during its propagation according to Eq. (2):

$\dot{m}_{O Z}=V_{O Z / \text { biomass }} . \quad \rho_{\text {biomass }}$

\subsubsection{Determination of apparent propagation velocity}

In the literature, a method to determine the apparent propagation velocity of the oxidation zone was first proposed by Ohlemiller and Lucca [21] and later on used by other authors [9,11,13]. It is based on the measurement of a temperature threshold to locate the $\mathrm{OZ}$ at a given position.

We tested and compared several criteria based on temperature measurements to locate the $\mathrm{OZ}$ and concluded that the maximum derivative of the temperature $(d T / d t)_{\max }$ was the most relevant and repeatable one. Thus, the oxidation zone is said to be located at a given thermocouple $\mathrm{T}_{\mathrm{i}}$ when $d T i / d t$ is maximum. We define the passage time $t_{O Z}{ }^{i}$ as the time corresponding to the passage of the $\mathrm{OZ}$ at elevation $\mathrm{i}$ (Fig. 4a).

Knowing the distance between two thermocouples $(10 \mathrm{~cm})$, it was then possible to plot the elevation of the oxidation zone in the reactor versus time (Fig. 4b). The apparent velocity was calculated as the derivative of this profile of $\mathrm{OZ}$ elevation versus time.

\subsubsection{Bed compaction velocity}

During upward propagation of the OZ, bed compaction was measured by a laser beam (Fig. 1). Fig. 4b shows the total bed height $h(t)$ as well as the elevation of $\mathrm{OZ}$ versus time.

Between 100 and $280 \mathrm{~min}$, the bed height slope remained constant. Towards the end of the experiment, the measured bed height appeared to fluctuate. This phenomenon is caused by radiation from the $\mathrm{OZ}$ which reaches the surface of the bed and disturbs the measurements made by the laser system.

For the discussion, we calculated the bed compaction rate, $C(t)$, versus time as follows:

$C(t)=\frac{h(t)-h\left(t_{0}\right)}{h\left(t_{0}\right)}$

where $h\left(t_{0}\right)$ is the bed height corresponding the moment that the $\mathrm{OZ}$ reaches $\mathrm{T} 7$ position ( $25 \mathrm{~cm}$ from the grate).

\subsection{Thickness of the oxidation zone}

Several ways to determine the thickness of the oxidation zone are reported in the literature. First, Fatehi and Kaviany [22] defined the front thickness as the length across which the chemical reaction rate was equal to or $>1 / 10$ of its maximum value. Second, working on municipal solid waste and wood chip combustion, Yang et al. [23] defined the reaction zone thickness as the physical distance in the flame front where the bed temperature rises from $30{ }^{\circ} \mathrm{C}$ to the peak value. Recently, Porteiro et al. [10] described these front thicknesses using temperature thresholds. For this purpose, the starting temperature of the heating and drying layer (drying front) was considered to be $303 \mathrm{~K}$; the final point of the drying and the start of the devolatilisation (devolatilisation front) was considered to be $373 \mathrm{~K}$. The temperature which determines the final stage of pyrolysis and the beginning point of the char reaction layer (ignition front) was assumed to be $773 \mathrm{~K}$. The end point of the char reaction layer was defined as when the temperature reached its maximum value.

In the present work, we propose to locate the top and the bottom surfaces of the OZ based on changes in temperature. The derivative of temperature versus time " $\mathrm{dT} / \mathrm{dt}$ " is proposed as the criterion. The time for the OZ top surface $t_{O Z}{ }^{\text {top }}$ at a given thermocouple (elevation) is when $\mathrm{dT} / \mathrm{dt}>5{ }^{\circ} \mathrm{Cmin}^{-1}$ while the time for the bottom surface $t_{O Z}{ }^{\text {bottom }}$ is when the temperature started to decrease, i.e. $\mathrm{dT} / \mathrm{dt}=0$. Then, the $\mathrm{OZ}$ thickness $\delta$ OZwas calculated as follows:

$\delta_{O Z}=\left(t_{O Z}^{\text {bottom }}-t_{O Z}^{\text {top }}\right) . V_{O Z / \text { reactor }}$

\section{Results and discussion}

\subsection{Air/biomass ratio and equivalence ratio}

The air mass flux was the same for all three types of biomass. We measured the average biomass consumption rate for each type (Table 2). These values allowed calculation of the parameters required for process operation and optimisation: the equivalence ratio and the air/biomass ratio. Biomass consumption rates and the ratios are also presented on a dry ash-free basis (daf) to facilitate the comparison.

The air/biomass ratio on daf basis was $0.76,0.64$ and 0.63 respectively for pine, miscanthus and wheat straw. The equivalence ratio (ER), defined as the actual air/biomass ratio relative to the stoichiometric air/biomass ratio, was calculated to be respectively, 0.14, 0.11, and 0.12 . The higher ER for the woody biomass than for the herbaceous biomasses shows that less woody biomass is consumed to sustain the $\mathrm{OZ}$ 
Table 2

Air/biomass ratio and equivalence ratio of the oxidative pyrolysis of the three biomasses.

\begin{tabular}{llll}
\hline Biomass & Pine & Miscanthus & Wheat straw \\
\hline Air mass flux $\left(\mathrm{kg} \mathrm{m}^{-2} \mathrm{~s}^{-1}\right)$ & 0.022 & 0.022 & 0.022 \\
$\begin{array}{l}\text { Average biomass consumption rate } \\
\quad\left(\mathrm{kg} \mathrm{m}^{-2} \mathrm{~s}^{-1}\right) \text { (daf) }\end{array}$ & 0.029 & 0.034 & 0.035 \\
Air/biomass ratio (daf) & 0.76 & 0.64 & 0.63 \\
Air/biomass stoichiometry (daf) & 5.39 & 5.66 & 5.34 \\
Equivalence ratio (daf) & 0.14 & 0.11 & 0.12 \\
\end{tabular}

propagation under the same air flux. Daouk et al. [4] carried out experiments with pine pellets using the same reactor in continuous operating mode and measured an air/biomass ratio on a dry basis of 0.68 . In our case, in batch mode, this ratio is clearly higher than their finding. Indeed, in continuous mode, the $\mathrm{OZ}$ is maintained stable in the reactor (by moving down the bed) and consequently remains in a hot zone. In batch mode, the OZ propagates towards a cold zone: heat losses are significantly higher. This result highlights the important role of the heat losses through the reactor walls during propagation of the OZ.

In addition, we investigated the impact of the moisture content of the biomass on these ratios. When the moisture content in the miscanthus pellets was reduced from 7.9 to $3.9 \%$, the air/biomass ratio $(d b)$ decreased from 0.62 to 0.38 and the ER from 0.11 to 0.08 . Indeed, the lower the water content of the biomass, the less energy is needed for drying and water/steam heating. As a consequence, the biomass consumption rate is higher in the case of dry biomass. In our case, dividing the moisture content by a factor 2 made it possible to increase the wood consumption rate by a factor 1.6 (from 0.036 to $0.057 \mathrm{~kg} \mathrm{~m}^{-2} \mathrm{~s}^{-1}$ ).

\subsection{Fine characterisation of the oxidation zone}

Here we compare the influence of the nature of the biomass on the

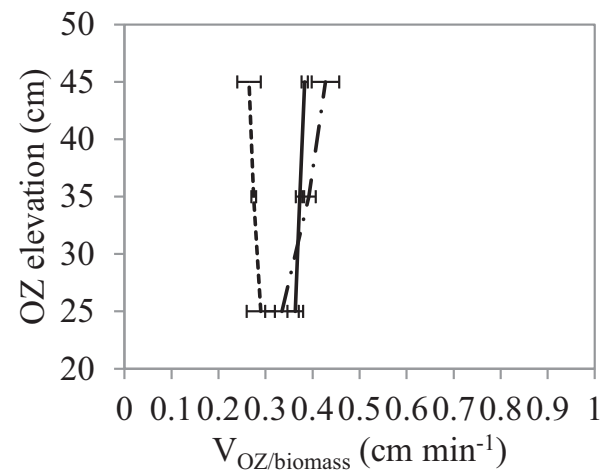

(a)

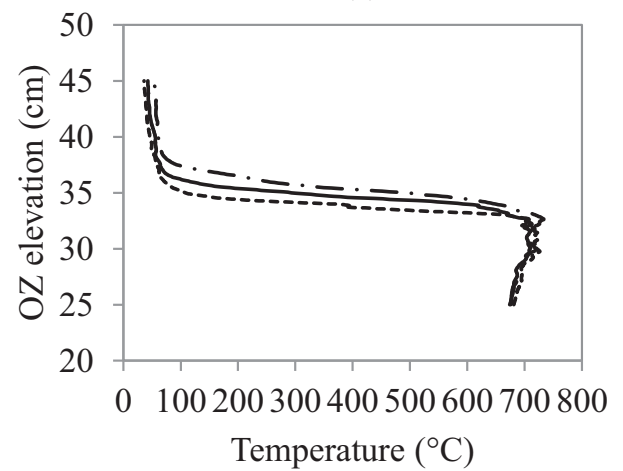

(c)
Table 3

Inlet and outlet flow rates $\left(\mathrm{kg} \mathrm{h}^{-1}\right)$ of the oxidative pyrolysis of the three biomasses.

\begin{tabular}{|c|c|c|c|c|c|}
\hline \multicolumn{3}{|c|}{ Flow rates $\left(\mathrm{kg} \mathrm{h}^{-1}\right)$} & \multirow{2}{*}{$\begin{array}{l}\begin{array}{l}\text { Pine } \\
\text { wood }\end{array} \\
3.17\end{array}$} & \multirow{2}{*}{$\begin{array}{l}\text { Miscanthus } \\
3.77\end{array}$} & \multirow{2}{*}{$\begin{array}{l}\text { Wheat } \\
\text { straw }\end{array}$} \\
\hline Inlet & Biomass, daf & & & & \\
\hline & Water (biomass) & & 0.22 & 0.31 & 0.36 \\
\hline & Oxygen (from air) & & 0.56 & 0.56 & 0.56 \\
\hline & Nitrogen (from air) & & 1.85 & 1.85 & 1.85 \\
\hline & Ash (from biomass) & & 0.01 & 0.12 & 0.34 \\
\hline \multirow[t]{11}{*}{ Outlet } & Char, daf & & 0.59 & 0.92 & 1.01 \\
\hline & $\begin{array}{l}\text { Condensates (by } \\
\text { difference) }\end{array}$ & & 1.70 & 1.35 & 1.62 \\
\hline & Drying water & & 0.22 & 0.31 & 0.36 \\
\hline & Permanent gases & $\mathrm{CO}_{2}$ & 0.90 & 1.29 & 1.17 \\
\hline & & $\mathrm{CO}$ & 0.15 & 0.58 & 0.36 \\
\hline & & $\mathrm{H}_{2}$ & 0.03 & 0.04 & 0.03 \\
\hline & & $\mathrm{CH}_{4}$ & 0.31 & 0.10 & 0.12 \\
\hline & & $\mathrm{C}_{2} \mathrm{H}_{4}$ & 0.03 & 0.03 & 0.03 \\
\hline & & $\mathrm{C}_{2} \mathrm{H}_{6}$ & 0.01 & 0.02 & 0.02 \\
\hline & Nitrogen & & 1.85 & 1.85 & 1.85 \\
\hline & Ash (from char) & & 0.01 & 0.12 & 0.34 \\
\hline
\end{tabular}

following important features of the OZ: effective propagation velocity, thickness, temperature, and compaction rate (Fig. 5). The results presented were obtained in the zone located $25-45 \mathrm{~cm}$ from the grate. Note that below and above this zone, the measurements were not repeatable, revealing non-stability of the $\mathrm{OZ}$ beyond this zone. The ignition took place $10 \mathrm{~cm}$ above the grate and the total biomass bed height at the end of the experiment was $55 \mathrm{~cm}$.

\subsubsection{Propagation velocity}

In Fig. 5a, effective velocity is plotted versus the height of the bed in the three biomass beds. These velocities can be considered constant along the study zone, as regards to the accuracy of the experiments. The

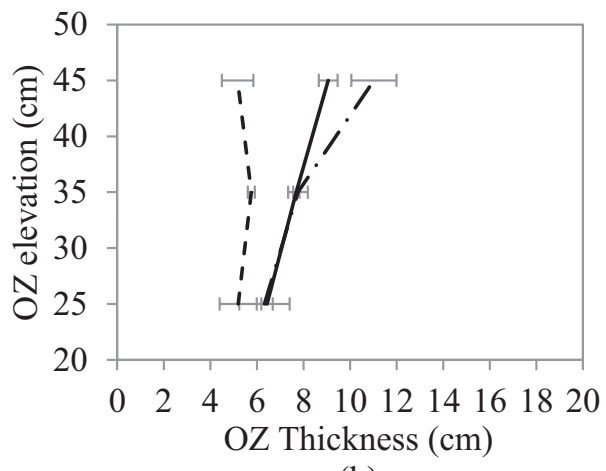

(b)

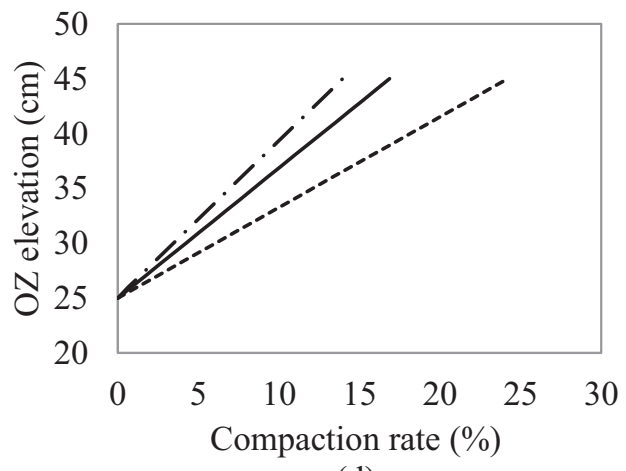

(d)

Fig. 5. OZ features in different pellet beds with $0.022 \mathrm{~kg} \mathrm{~m}^{-2} \mathrm{~s}^{-1}$ air flux. a) Propagation velocity, b) Thickness, c) Temperature, d) Compaction rate. The dashed line represents pine; the solid line represents miscanthus; the dashed-dotted line represents wheat straw. 


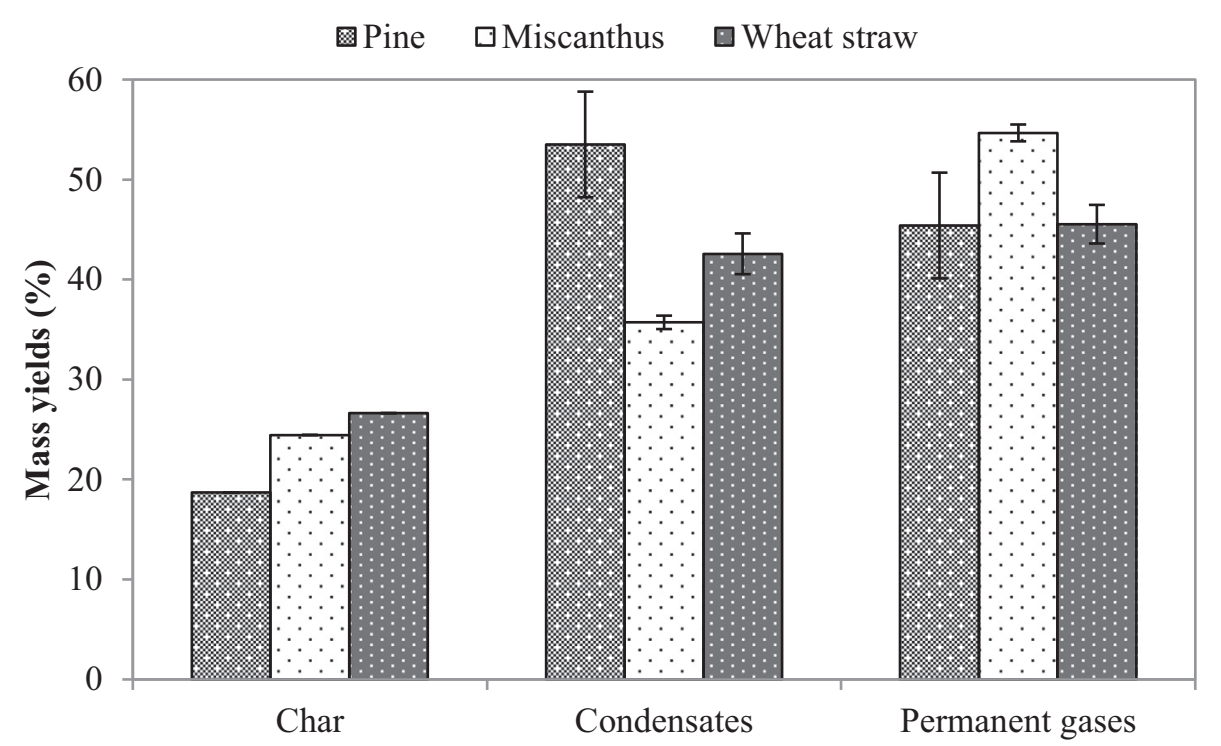

Fig. 6. Mass yields (daf) of the oxidative pyrolysis products from different biomasses, $0.022 \mathrm{~kg} \mathrm{~m}^{-2} \mathrm{~s}^{-1}$ air flux.

Table 4

Proximate and ultimate analysis of the char produced by oxidative pyrolysis of the three biomasses, $0.022 \mathrm{~kg} \mathrm{~m}^{-2} \mathrm{~s}^{-1}$ air flux.

\begin{tabular}{llll}
\hline \multicolumn{1}{l}{ Charcoal } & Pine wood & Miscanthus & Wheat straw \\
\hline Proximate analysis $(\mathrm{wt} \%, \mathrm{db})$ & 1.5 & & \\
Ash & 6.75 & 11.2 & 25.0 \\
Volatile matter & 91.8 & 6.4 & 9.5 \\
Fixed carbon & 82.4 & 65.5 \\
Ultimate analysis (wt $\%$, daf) & 94.4 & & \\
$\mathrm{C}$ & 2.0 & 91.2 & 88.5 \\
$\mathrm{H}$ & 0.4 & 1.8 & 1.8 \\
$\mathrm{~N}$ & 3.3 & 0.5 & 1.6 \\
O (by difference) & 33.4 & 6.6 & 8.1 \\
LHV (MJ kg & & \\
\end{tabular}

profile of the wheat straw pellet bed (dashed-dotted line) suggests that the stationary regime is not fully reached at a distance of $35 \mathrm{~cm}$ from the grate, compared to the two other biomass pellet beds. The effective velocity was lower in the wood pellet bed than in the two other beds. The average velocity was $0.28,0.37$, and $0.39 \mathrm{~cm} \mathrm{~min}^{-1}$ in the beds of pine, miscanthus and wheat straw pellets, respectively. As a consequence, the effective propagation rate was calculated as $0.031,0.036$, $0.036 \mathrm{~kg} \mathrm{~m}^{-2} \mathrm{~s}^{-1}$. These values are in agreement with the average biomass consumption rate calculated by weighing (Table 2). This agreement validates the method for the determination of effective velocity.

Explaining the difference in OZ propagation velocity is complex because it is controlled by many factors related to biomass/bed properties. In our tests, bed bulk density ranged from $549 \mathrm{~kg} \mathrm{~m}^{-3}$ for wheat straw pellets to $657 \mathrm{~kg} \mathrm{~m}^{-3}$ for wood pellets, and could impact the velocity. Porteiro et al. [13] compared velocities in a wide range of bulk densities, under higher air flux than in the present study. They showed that velocity decreased from $2.5 \mathrm{~cm} \mathrm{~min}^{-1}$ to $0.7 \mathrm{~cm} \mathrm{~min}^{-1}$ with an increase in bulk density from 150 to $350 \mathrm{~kg} \mathrm{~m}^{-3}$. Above this density range, velocity decreased much more slowly and remained close to $0.5 \mathrm{~cm} \mathrm{~min}^{-1}$. Indeed, the same authors measured a slight drop (of about 5\%) in velocity in the pellet beds when the bulk density was increased from 600 to $700 \mathrm{~kg} \mathrm{~m}^{-3}$. Compared to our experiment, their results show that in the same range of bed density, lower propagation velocities (from 0.28 to $0.39 \mathrm{~cm} \mathrm{~min}^{-1}$ ) are obtained with low air flux. We obtained a sharper decrease in the propagation velocity, i.e. of about $25 \%$, when we changed the bulk density from $549 \mathrm{~kg} \mathrm{~m}^{-3}$ with wheat straw pellets to $657 \mathrm{~kg} \mathrm{~m}^{-3}$ with wood pellets. Nevertheless, despite the higher sensitivity of the propagation velocity to the bulk density that we observed, which could also be explained by our specific very low air mass flux conditions, we believe that other properties of the biomass have a greater impact. Indeed, the ash in the biomass, which influences the thermal properties of the bed (conductivity or emissivity) and reaction kinetics (inhibition and/or catalytic effects), is certainly the main factor responsible for the difference measured in the propagation velocity between woody and herbaceous biomass.

\subsubsection{Oxidation zone thickness}

Regarding the OZ thickness (Fig. 5b), it was $5.7 \mathrm{~cm}$ for the pine bed and $7.8 \mathrm{~cm}$ for miscanthus and wheat straw bed. The lower propagation velocity in the wood bed (higher air/biomass ratio) associated with its higher density can explain this difference. In addition, the thickness of the $\mathrm{OZ}$ increased until a distance of $35 \mathrm{~cm}$ above the grid, and then stabilized in the wood bed showing that stationary propagation was reached. In the case of wheat straw, the stationary regime could not be completely reached.

It is possible to understand the behaviour of the $\mathrm{OZ}$ thickness by comparing our results with the literature. Porteiro et al. [10] measured the thickness of the reaction front (similar to what we call the oxidation zone in our work) in counter-current smouldering in a bed of wood pellets with a density of $690 \mathrm{~kg} \mathrm{~m}^{-3}$. They assumed that the main processes occurring in the reaction front do not overlap and are defined by threshold temperatures. They described a reaction front with three

Table 5

ICP analysis of ash content in the three biomasses.

\begin{tabular}{|c|c|c|c|c|c|c|c|c|c|c|}
\hline ppm, $d b$ & $\mathrm{SiO}_{2}$ & $\mathrm{Cl}$ & $\mathrm{P}$ & $\mathrm{K}$ & $\mathrm{Ca}$ & $\mathrm{Mg}$ & $\mathrm{Fe}$ & $\mathrm{Na}$ & $\mathrm{Zn}$ & $\mathrm{Al}$ \\
\hline Pine & 1,540 & 80 & 39 & 510 & 710 & 240 & 0.4 & 0.6 & 0.1 & 0.4 \\
\hline Miscanthus & 12,600 & 360 & 350 & 4,000 & 3,180 & 530 & 1.7 & 1.3 & 0.1 & 2.3 \\
\hline Wheat straw & 47,300 & 1,450 & 1,320 & 10,180 & 3,800 & 820 & 1.9 & 2.3 & 0.1 & 2.3 \\
\hline
\end{tabular}


different zones: drying zone, devolatilisation zone, and char reaction zone corresponding to the threshold temperatures of $100{ }^{\circ} \mathrm{C}, 500{ }^{\circ} \mathrm{C}$, and Tmax, respectively. Their results showed that the thickness of each of the two first zones was about $5 \mathrm{~mm}$ whatever the air flux. The thickness of the char reaction zone they measured ranged from 10 to $15 \mathrm{~mm}$ with an air flux $>0.12 \mathrm{~kg} \mathrm{~m}^{-2} \mathrm{~s}^{-1}$. But when the air flux was reduced to $0.07 \mathrm{~kg} \mathrm{~m}^{-2} \mathrm{~s}^{-1}$ the thickness of the char reaction zone increased to $40 \mathrm{~mm}$. In the present work, the thickness of the $\mathrm{OZ}$ we measured based on the derivative of the temperature should be compared to the sum of the three zones defined by Porteiro et al. To summarise, when propagating under a low air flux $\left(0.022 \mathrm{~kg} \mathrm{~m}^{-2} \mathrm{~s}^{-1}\right)$, the global OZ was slightly thicker than with a higher air flux.

\subsubsection{Temperature field}

A temperature profile along the bed height can be calculated from the temperature profiles measured by a given thermocouple (Fig. 2) and an average value of the propagation velocity can be determined. Fig. $5 \mathrm{c}$ shows the temperature profile in the bed of three biomasses when the $\mathrm{OZ}$ is at a height of $35 \mathrm{~cm}$. Comparing the three biomasses, it is remarkable that no difference in temperature was observed, despite significant differences particularly in properties such as ash content or heating value. The temperature increased from $50{ }^{\circ} \mathrm{C}$ to a peak of around $720^{\circ} \mathrm{C}$, and then decreased slowly and regularly along the char bed. This decrease is due to heat losses through the reactor walls and possibly to char gasification by vapour. In most of the previous studies on smouldering, the maximum temperatures of a propagation front have been reported to be higher than $800^{\circ} \mathrm{C}[9,14,21]$. The reason is that the experiments were generally carried out in conditions close to stoichiometric combustion to fit a fixed bed incinerator. In our experiments, oxidative pyrolysis was performed in high sub-stoichiometric conditions, using only $11 \%$ to $14 \%$ of the stoichiometric combustion air, which resulted in a lower peak temperature. These temperature profiles, associated with $\mathrm{OZ}$ velocity and thickness provide information on the heating rate, which is known to strongly influence the yields of the pyrolysis products. The average heating rate was calculated to be $20-35{ }^{\circ} \mathrm{C} \mathrm{min}^{-1}$ in all the experiments.

\subsubsection{Bed compaction}

Compaction occurred in our experiments during the $\mathrm{OZ}$ propagation in all three biomass pellet beds (Fig. 5d). The compaction rate, plotted versus the elevation of the $\mathrm{OZ}$, corresponds to the ratio of the decrease in the bed height to the initial bed height. At the end of the experiment, i.e. $45 \mathrm{~cm}$ from the grate, the compaction rate was $24 \%, 17 \%$, and $14 \%$ for the pine, miscanthus and wheat straw beds, respectively. Bed compaction can be caused by a reduction in the size of the pellets during the reaction (particle shrinkage), rearrangment of the particles, or to fragmentation. However, as shown in Fig. 4b, in our experiments, compaction of the bed was linear, revealing that the bed was quite static and that the impacts of particle rearrangment, and fragmentation were negligible. Thus, particle shrinkage was clearly the main phenomenon responsible for bed compaction.

In order to determine particle shrinkage, we measured the average diameter of biomass pellets to be $6.08 \mathrm{~mm}, 6.28 \mathrm{~mm}, 5.56 \mathrm{~mm}$, and the average diameter of the char after oxidative pyrolysis to be $4.35 \mathrm{~mm}$, $4.80 \mathrm{~mm}, 4.37 \mathrm{~mm}$, for pine, miscanthus and wheat straw, respectively. The reduction in particle diameter was then calculated be $28 \%, 24 \%$ and $21 \%$. These values are in line with several studies focused on particle shrinkage of pelletized biomass during pyrolysis, with a temperature range of $300-800{ }^{\circ} \mathrm{C}[24,25]$.

The difference in ash content may be linked to the differences in the shrinkage of the three biomasses. Indeed, the higher the ash content, the less the particle shrinks during pyrolysis. Nevertheless, the particle volume shrinkage, calculated to be $63 \%, 55 \%$ and $51 \%$ for pine, miscanthus and wheat straw, respectively, is considerably higher than the measured compaction rate of the bed. This observation shows that, as the char bed is static, the rearrangment of the particle does not occur efficiently and that the intra-particle porosity is consequently considerably higher in the char beds than in the biomass beds.

\subsubsection{Influence of moisture content}

The influence of moisture content was also investigated. We performed experiments with a bed of miscanthus pellets dried to $3.9 \%$ moisture content and compared the $\mathrm{OZ}$ features to those of the reference miscanthus pellets (7.9\% moisture content). The effective propagation velocity in the "dried" miscanthus bed was $10 \%$ higher. The lower velocity is probably caused by the drying process which delays the devolatilisation and oxidation reactions. This result is consistent with the increase in the ER (from 0.08 to 0.11 ) measured when the moisture content was higher. Indeed, as the air flux was the same in the two cases, the decrease in the oxidation zone velocity explains the higher ER with a higher moisture content.

Comparing the thicknesses of the $\mathrm{OZ}$ with the dried pellets and with the reference miscanthus pellets, it is worth noting that using dried pellets allows a stationary regime to be reached faster, as shown by the stabilisation of the thickness. Nevertheless, no significant difference was observed in the thickness with a moisture content within the range of 4 to $8 \%$.

We also measured the temperature profile in the $\mathrm{OZ}$ in the bed of dried miscanthus pellets. In our high sub-stoichiometric conditions, the peak temperature, around $720^{\circ} \mathrm{C}$, was shown to be independent of moisture content. This result is in agreement with the results of experiments reported in the literature in stoichiometric conditions [16]. In that case, peak temperatures were $1300^{\circ} \mathrm{C}$, similar to the calculated adiabatic end of combustion temperatures. Finally, the compaction of the bed was not affected by the moisture content of the biomass, which ranged from 4 to $8 \%$. Shrinking of the particle was measured in the same way after oxidative pyrolysis of the wet and dried miscanthus pellets.

\subsection{Yields and composition of the char, condensates, and permanent gases}

Gases were sampled during the propagation of $\mathrm{OZ}$ over $20 \mathrm{~cm}$, from T7 to T5, to ensure the stationary regime had been reached.

The nitrogen mass flow rate in the feed air $\left(\dot{\mathrm{m}}_{\mathrm{N}_{2, \mathrm{i}}}\right)$ was used as a tracer to calculate the total mass flow rate of permanent gases $\left(\dot{m}_{p g}\right)$ at the outlet of the reactor according to Eq. (5).

$\dot{m}_{p g}=\frac{\dot{m}_{N_{2, i}}}{F_{N_{2, o}}}$

where $F_{N_{2,}}$ represents the nitrogen mass fraction in the permanent gases measured by the micro-GC. The mass flow rates of each component $\left(\dot{\mathrm{m}}_{\mathrm{j}, \mathrm{o}}\right)$ in the permanent gases (pg) was calculated using Eq. (6).

$$
\begin{aligned}
\dot{m}_{j, o}= & F_{j, o} . \dot{m}_{p g} \\
& \quad \mathrm{j}=\left\{\mathrm{O}_{2}, \mathrm{CO}_{2}, \mathrm{CO}, \mathrm{H}_{2}, \mathrm{CH}_{4}, \mathrm{C}_{2} \mathrm{H}_{2}, \mathrm{C}_{2} \mathrm{H}_{6}\right\}
\end{aligned}
$$

The total mass of biomass fed into the reactor was weighed beforehand. Knowing the total duration of the experiment, we calculated the average biomass consumption flux $\dot{m}_{b}$ (in $\mathrm{kg} \mathrm{m}^{-2} \mathrm{~s}^{-1}$ ). We calculated the char production flux $\dot{m}_{c h}\left(\right.$ in $\mathrm{kg} \mathrm{m}^{-2} \mathrm{~s}^{-1}$ ) using the ash tracer method as follows:

$\dot{m}_{c h}=\frac{\dot{m}_{b} . A S H_{b}}{A S H_{c h}}$

where $\mathrm{ASH}_{\mathrm{b}}$ and $\mathrm{ASH}_{\mathrm{ch}}$ are the ash fraction in the biomass and char, respectively.

Yields of char (ch) and of permanent gases were measured with high accuracy and are expressed as percentages of the mass of biomass on a daf basis:

$Y_{k}=\left(\frac{\dot{m_{k}}}{\dot{m_{b}}}\right)_{d a f} \mathrm{k}=\mathrm{ch}, \mathrm{pg}$ 
We determined the yield of condensates by the difference between the inlet mass (biomass and air) and outlet mass (char and permanent gases) because weighing the condensate in the impingers was shown to be too imprecise because of its high dilution in isopropanol.

The heating values of the biomass and the chars were measured with a calorimeter (Parr Instrument, Parr-6200). The heating value of the permanent gas was calculated from the measured concentration of each individual gas and their respective standard enthalpies [26].

Mass balances were determined from the experimental results by considering the products entering and leaving the oxidation zone in the beds with the three different biomasses (Table 3). The presented values are the average of at least three tests for each biomass, with a discrepancy $<10 \%$ in each flow rate. The total inlets and outlets were exactly the same as the flow rates of the condensates and were calculated by difference.

The yield of the char, condensates and permanent gases were calculated as a percentage of the mass of daf biomass and plotted (Fig. 6). Note that the sum of the measured yields (char, condensates, permanent gases) exceeded $100 \%$. This is because oxygen from the air reacts inside the bed and is recovered in the pyrolysis products.

As can be seen in Fig. 6, the yield of pine, miscanthus and wheat straw char was $18.7 \%, 24.5 \%$ and $26.6 \%$, respectively. The yield of permanent gas ranged from 46 to $54 \%$, and the highest yield was obtained from miscanthus pyrolysis. The yield of condensates from the pine pyrolysis was significantly higher, 53.5\%. There are many factors affect the yields of the products [27]. Nevertheless, these differences cannot be explained by the difference in peak temperatures and heating rates during pyrolysis as we showed that the operating conditions were almost the same for the three biomasses. The explanation may lie in the difference in the ash content and its composition [28]. Indeed, biomass particles shrink during pyrolysis and the ash tends to concentrate on the external surface thereby creating a thin layer of ash surrounding the particle. The catalytic effects of the ash layer accelerate secondary charforming reactions (i.e. condensation, cross-linking and repolymerisation) and favour the cracking of heavy organic compounds. As a consequence, there is an increase in char yield and a reduction in the yield of condensates [29-33].

Ash not only affects the yield but also the composition of the char (Table 4). The chars produced by oxidative pyrolysis of the three biomasses were all rich in carbon since they contained 94.4\%, 91.2 and $88.5 \%$ of carbon for pine, miscanthus and wheat straw, respectively. High carbon and low oxygen contents are responsible for the high heating values of the resulting chars. The oxygen content of the produced pine, miscanthus and wheat straw chars was 3.3\%, 6.6\% and $8.1 \%$, respectively. This result can be explained by the catalytic effects of ash on the formation of the secondary char by the condensation/ polymerisation of the primary tar and the interaction between the resulting volatiles and char. Song et al. [34] showed that during the adsorption and subsequent conversion of tar molecules by char, some $\mathrm{O}$ containing species originating from tar are transferred to the char and form additional O-containing structures in the char matrix.

Some specific elements in the ash play an important role in the biomass pyrolysis process. As reported in the literature [29,32,33], potassium in particular has a significant influence on the char formation stage by increasing the char yield [23,35]. Regarding volatile products, Pan and Richards [29] reported that they act as a catalyst in pyrolytic reactions, resulting in the formation of carbon dioxide and carbon monoxide. What is more, the reactivity of the alkaline metal compounds decreases in the presence, ranked in order of importance of $\mathrm{K}, \mathrm{Na}, \mathrm{Ca}, \mathrm{Mg}, \mathrm{Al}, \mathrm{Zn}, \mathrm{Fe}$. Regarding the three biomasses studied here, Table 5 shows that the amounts of $\mathrm{Al}, \mathrm{Zn}$ and Fe are very small compared to those of $\mathrm{K}$ and $\mathrm{Ca}$. Thus, the high concentration of potassium confirms its role in the pyrolysis yields of three different biomasses.

Some authors $[36,37]$ have also demonstrated the catalytic effect of ashes on char oxidation reactions. In our study, the yield of char from oxidative pyrolysis of ash-rich (herbaceous) biomass was shown to be higher than the yield of low-ash biomass. This observation suggests that no significant oxidation of char occurred during oxidative pyrolysis under a low air mass flux of $0.022 \mathrm{~kg} \mathrm{~m}^{-2} \mathrm{~s}^{-1}$. This conclusion is of importance with respect to the $\mathrm{OZ}$ propagation phenomena as it shows that only oxidation of volatile matter provides the energy for the process. This result is in a good agreement with the conclusions of previous works at higher air mass fluxes $[10,17,38]$.

\section{Conclusions}

A comparative oxidative pyrolysis in fixed bed of three biomasses highlighted that the oxidation zone's velocity and thickness are $25 \%$ lower for wood pellets than for miscanthus or wheat straw pellets. Ash has a significant impact on the process by slowing down the propagation velocity and catalyzing reactions that affect pyrolysis products composition and yields. Under a low air mass flux of $0.022 \mathrm{~kg} \mathrm{~m}^{-2} \mathrm{~s}^{-1}$, the OZ consumed $11 \%$ to $14 \%$ of the stoichiometric air to self-sustain the process. The peak temperature, about $720^{\circ} \mathrm{C}$, is not sensitive to the biomass nature. A significant compaction took place in all biomass beds, ranging from 14 to $24 \%$. In addition, increasing biomass moisture content results in a higher equivalence ratio and a lower propagation velocity.

\section{References}

[1] C. Erlich, T.H. Fransson, Downdraft gasification of pellets made of wood, palm-oil residues respective bagasse: experimental study, Appl. Energy 88 (2011) 899-908, http://dx.doi.org/10.1016/j.apenergy.2010.08.028.

[2] M. Simone, F. Barontini, C. Nicolella, L. Tognotti, Gasification of pelletized biomass in a pilot scale downdraft gasifier, Bioresour. Technol. 116 (2012) 403-412, http:// dx.doi.org/10.1016/j.biortech.2012.03.119.

[3] M. Ouadi, J.G. Brammer, M. Kay, A. Hornung, Fixed bed downdraft gasification of paper industry wastes, Appl. Energy 103 (2013) 692-699, http://dx.doi.org/10. 1016/j.apenergy.2012.10.038.

[4] E. Daouk, L. Van de Steene, F. Paviet, E. Martin, J. Valette, S. Salvador, Oxidative pyrolysis of wood chips and of wood pellets in a downdraft continuous fixed bed reactor, Fuel 196 (2017) 408-418, http://dx.doi.org/10.1016/j.fuel.2017.02.012.

[5] E.R. Carvalho, C.A. Gurgel Veras, J.A. Carvalho, Experimental investigation of smouldering in biomass, Biomass Bioenergy 22 (2002) 283-294, http://dx.doi.org/ 10.1016/S0961-9534(02)00005-3.

[6] F. De Souza Costa, D. Sandberg, Mathematical model of a smoldering log, Combust. Flame 139 (2004) 227-238, http://dx.doi.org/10.1016/j.combustflame.2004.07. 009.

[7] T.J. Ohlemiller, Modeling of smoldering combustion propagation, Prog. Energy Combust. Sci. 11 (1985) 277-310, http://dx.doi.org/10.1016/0360-1285(85) 90004-8.

[8] M.A. Nolter, D.H. Vice, Looking back at the Centralia coal fire: a synopsis of its present status, Int. J. Coal Geol. 59 (2004) 99-106, http://dx.doi.org/10.1016/j. coal.2003.12.008.

[9] C. Ryu, Y. Bin Yang, A. Khor, N.E. Yates, V.N. Sharifi, J. Swithenbank, Effect of fuel properties on biomass combustion: part I. Experiments-fuel type, equivalence ratio and particle size, Fuel 85 (2006) 1039-1046, http://dx.doi.org/10.1016/j.fuel. 2005.09.019.

[10] J. Porteiro, D. Patiño, J.L. Miguez, E. Granada, J. Moran, J. Collazo, Study of the reaction front thickness in a counter-current fixed-bed combustor of a pelletised biomass, Combust. Flame 159 (2012) 1296-1302, http://dx.doi.org/10.1016/j. combustflame.2011.10.007.

[11] S. Mahapatra, S. Dasappa, Experiments and analysis of propagation front under gasification regimes in a packed bed, Fuel Process. Technol. 121 (2014) 83-90, http://dx.doi.org/10.1016/j.fuproc.2014.01.011.

[12] S. Zhao, Y. Luo, Y. Su, Y. Zhang, Y. Long, Experimental investigation of the oxidative pyrolysis mechanism of pinewood on a fixed-bed reactor, Energy Fuel 28 (2014) 5049-5056, http://dx.doi.org/10.1021/ef500612q.

[13] J. Porteiro, D. Patiño, J. Collazo, E. Granada, J. Moran, J.L. Miguez, Experimental analysis of the ignition front propagation of several biomass fuels in a fixed-bed combustor, Fuel 89 (2010) 26-35, http://dx.doi.org/10.1016/j.fuel.2009.01.024.

[14] J. Porteiro, D. Patiño, J. Moran, E. Granada, Study of a fixed-bed biomass combustor: influential parameters on ignition front propagation using parametric analysis, Energy Fuel 24 (2010) 3890-3897, http://dx.doi.org/10.1021/ef100422y.

[15] D. Shin, S. Choi, The combustion of simulated waste particles in a fixed bed, Combust. Flame 121 (2000) 167-180, http://dx.doi.org/10.1016/S0010-2180(99) 00124-8.

[16] J.J. Saastamoinen, R. Taipale, M. Horttanainen, P. Sarkomaa, Propagation of the ignition front in beds of wood particles, Combust. Flame 123 (2000) 214-226, http://dx.doi.org/10.1016/S0010-2180(00)00144-9.

[17] M. Milhé, L. van de Steene, M. Haube, J.-M. Commandré, W.-F. Fassinou, G. Flamant, Autothermal and allothermal pyrolysis in a continuous fixed bed reactor, J. Anal. Appl. Pyrolysis 103 (2013) 102-111, http://dx.doi.org/10.1016/j. 
jaap.2013.03.011.

[18] G. Teixeira, L. Van de Steene, S. Salvador, F. Gelix, J.-L. Dirion, F. Paviet, Gasification of continuous wood char bed: modelling and experimental approach, Chem. Eng. Trans. 37 (2014) 247-252 (a Publication of AIDIC), https://doi.org/10. 3303/CET1437042.

[19] W. Van de Kamp, P. De Wild, U. Zielke, M. Suomalainen, H. Knoef, J. Good, T. Liliedahl, C. Unger, M. Whitehouse, J. Neeft, H. van den Hoek, J. Kiel, Tar measurement standard for sampling and analysis of tars and particles in biomass gasification product gas, Proceedings of the 14th European Biomass Conference and Exhibition, 2005, pp. 791-794.

[20] G. Teixeira, L. Van De Steene, E. Martin, F. Gelix, S. Salvador, Gasification of cha from wood pellets and from wood chips: textural properties and thermochemical conversion along a continuous fixed bed, Fuel 102 (2012) 514-524, http://dx.doi. org/10.1016/j.fuel.2012.05.039.

[21] T.J. Ohlemiller, D.A. Lucca, An experimental comparison of forward and reverse smolder propagation in permeable fuel beds, Combust. Flame 54 (1983) 131-147, http://dx.doi.org/10.1016/0010-2180(83)90027-5.

[22] M. Fatehi, M. Kaviany, Adiabatic reverse combustion in a packed bed, Combust Flame 99 (1994) 1-17, http://dx.doi.org/10.1016/0010-2180(94)90078-7.

[23] Y.B. Yang, H. Yamauchi, V. Nasserzadeh, J. Swithenbank, Effects of fuel devolatilisation on the combustion of wood chips and incineration of simulated municipa solid wastes in a packed bed 角, Fuel 82 (2003) 2205-2221, http://dx.doi.org/10. 1016/S0016-2361(03)00145-5.

[24] R. Paulauskas, N. Striūgas, E. Misiulis, Experimental and Theoretical Investigation of Wood Pellet Shrinkage During Pyrolysis, (2014), pp. 1-11.

[25] R. Paulauskas, N. Striūgas, K. Zakarauskas, A. Džiugys, L. Vorotinskienė, Investigation of regularities of pelletized biomass thermal deformations during pyrolysis, Therm. Sci. (2017) 90-90 (OnLine-Fir), doi.org/10.2298/ TSCI160916090P.

[26] T. Waldheim, L. Nilsson, Heating Value of Gases From Biomass Gasification, IEA Bioenergy Agreement, Task 20 - Thermal Gasification of Biomass, 61 (2001) http:// www.ieatask33.org/app/webroot/files/file/publications/HeatingValue.pdf.

[27] A. Anca-Couce, Reaction mechanisms and multi-scale modelling of lignocellulosic biomass pyrolysis, Prog. Energy Combust. Sci. 53 (2016) 41-79, http://dx.doi.org/ 10.1016/j.pecs.2015.10.002.

[28] A. Hlavsová, A. Corsaro, H. Raclavská, S. Vallová, D. Juchelková, The effect of feedstock composition and taxonomy on the products distribution from pyrolysis of nine herbaceous plants, Fuel Process. Technol. 144 (2016) 27-36, http://dx.doi. org/10.1016/j.fuproc.2015.11.022

[29] W.P. Pan, G.N. Richards, Influence of metal ions on volatile products of pyrolysis of wood, J. Anal. Appl. Pyrolysis 16 (1989) 117-126, http://dx.doi.org/10.1016/ 0165-2370(89)85011-9.

[30] N. Tröger, D. Richter, R. Stahl, Effect of feedstock composition on product yields and energy recovery rates of fast pyrolysis products from different straw types, J. Anal. Appl. Pyrolysis 100 (2013) 158-165, http://dx.doi.org/10.1016/j.jaap.2012. 12.012.

[31] Y. Lee, J. Park, C. Ryu, K.S. Gang, W. Yang, Y.K. Park, J. Jung, S. Hyun, Comparison of biochar properties from biomass residues produced by slow pyrolysis at $500^{\circ} \mathrm{C}$, Bioresour. Technol. 148 (2013) 196-201, http://dx.doi.org/10.1016/j.biortech. 2013.08.135.

[32] W.F. DeGroot, F. Shafizadeh, The influence of exchangeable cations on the carbonization of biomass, J. Anal. Appl. Pyrolysis 6 (1984) 217-232, http://dx.doi.org/ 10.1016/0165-2370(84)80019-4.

[33] D.J. Nowakowski, J.M. Jones, R.M.D. Brydson, A.B. Ross, Potassium catalysis in the pyrolysis behaviour of short rotation willow coppice, Fuel 86 (2007) 2389-2402, http://dx.doi.org/10.1016/j.fuel.2007.01.026.

[34] Y. Song, Y. Zhao, Destruction of tar during volatile-char interactions at low temperature, Fuel Process. Technol. 171 (2018) 215-222, http://dx.doi.org/10.1016/j. fuproc.2017.11.023.

[35] W. Zhao, Z. Li, G. Zhao, F. Zhang, Q. Zhu, Effect of air preheating and fuel moisture on combustion characteristics of corn straw in a fixed bed, Energy Convers. Manag. 49 (2008) 3560-3565, http://dx.doi.org/10.1016/j.enconman.2008.07.006.

[36] C. Zou, J. Zhao, X. Li, R. Shi, Effects of catalysts on combustion reactivity of anthracite and coal char with low combustibility at low/high heating rate, J. Therm. Anal. Calorim. 126 (2016) 1469-1480, http://dx.doi.org/10.1007/s10973-0165806-y.

[37] Z.A. Mayer, A. Apfelbacher, A. Hornung, A comparative study on the pyrolysis of metal- and ash- enriched wood and the combustion properties of the gained char, J. Anal. Appl. Pyrolysis 96 (2012) 196-202

[38] M. Kim, Y. Lee, J. Park, C. Ryu, T.I. Ohm, Partial oxidation of sewage sludge briquettes in a updraft fixed bed, Waste Manag. 49 (2016) 204-211, http://dx.doi.org/ 10.1016/j.wasman.2016.01.040. 